\title{
Identifying factors influencing demolition waste generation in Hong Kong
}

$\mathrm{Xi} \mathrm{Chen}{ }^{1}$ and Weisheng $\mathrm{Lu}^{2, *}$

${ }^{1}$ Department of Real Estate and Construction, The University of Hong Kong, Pokfulam, Hong Kong SAR, P.R. China

2, * Department of Real Estate and Construction, The University of Hong Kong, Pokfulam, Hong Kong SAR, P.R. China; The University of Hong Kong Shenzhen Institute of Research and Innovation (SIRI), B402, Shenzhen Virtual University Park, Nanshan District, Shenzhen, China.

\begin{abstract}
As demolition normally generates the largest proportion of construction and demolition (C\&D) waste, more importance should be attached to it for effective $C \& D$ waste management. Previous studies have attempted to understand demolition waste generation (DWG) but the understanding remains relatively insufficient, in large part due to the erratic and poor quality data available. This research aims to identify factors impacting DWG by making use of a big dataset which has recently become available as a result of $C \& D$ waste management practices in Hong Kong. Using big data analytics, it is confirmed that DWG, demolition cost, and duration of conducting the demolition work are dependent on each other. It is also found that geographical location, building usage, and the public-private nature of a building also have a significant impact on DWG in the Hong Kong context. Based on the correlations between DWG and these identified factors, stakeholders may introduce proper managerial or policy interventions to effectively minimize DWG. For example, public policy-makers may formulate more tailor-made regulations to attach more importance to the locations, usages and public-private nature, which have more potentials for demolition waste minimization.
\end{abstract}

Keyword: Construction waste management; Demolition waste; Waste generation (DWG); Big data; Hong Kong

\section{Introduction}

Construction and demolition (C\&D) waste, is defined as the surplus and damaged products and materials that arise from construction, renovation, and demolition activities (Roche and Hegarty, 2006). In some settings, 'C\&D waste' and 'construction waste' are used interchangeably for simplicity, or when the sources of waste are not the focus. In economically developed countries, demolition activities may be limited. For example, Bergsdal et al. (2007) reported that in Norway demolition comprised just $8 \%$ of national C\&D activities $\left(\mathrm{m}^{2} /\right.$ year) in 1998 , while new construction and renovation comprised $52 \%$ and $40 \%$ respectively. By contrast, demolition in economically developing economies is often extensive when existing structures are demolished to provide new land for the urgent demands of housing and other facilities (Lu et al., 2016c). In Shanghai, for example, the demolition floor area in 2014 reached $1,185,800 \mathrm{~m}^{2}$, declining from 2008's plateau (SSB, 2015). In many developing and developed countries or cities, demolition is 
a quite wasteful activity. For example, in the UK, the waste amount from C\&D activities has remained at around 100 million tons annually in recent years (DEFRA, 2015), while demolition accounted for around 32.7 million tons in 2007 (CRWP, 2009), which means demolition waste takes about $30 \%$ of all annual construction waste generated in UK. Another developed country Norway logged 1.8 million tons of C\&D waste generated in 2013, 31.3\% of which was from demolition activities (Statistics Norway, 2015). In China, annual C\&D waste generation reportedly reached one billion tons in $2013,74 \%$ of which resulted from demolition activities (NDRC, 2014; Lu et al., 2016c). Demolition in Hong Kong is estimated to produce, by weight, more than 10 times the amount of waste produced from construction of new buildings (Poon et al., 2001; Lu et al., 2015). Minimizing demolition waste is thus often a priority in mitigating the adverse impacts caused by construction waste, including land deterioration (Ofori, 1992), resource depletion (Kofoworola and Gheewala, 2009; Ferguson, 1995), and various forms of pollution such as noise, dust, air pollution and discharge of toxic waste (Lu and Yuan, 2011).

Previous studies have attempted to understand the nature of DWG. This can be investigated at either project level or regional level (Bergsdal et al., 2007; Llatas, 2011; Yost and Halstead, 1996; Andersen et al., 2007; Bergsdal et al., 2007; Bohne et al., 2008). It is important to understand DWG at a project level mainly for two reasons. First, construction works, either new building, renovation, or demolition, are normally organized as projects. Second, by summing up DWG of various projects, it is able to understand the overall nature of DWG of a region. Lu et al. (2011) investigated factors affecting C\&D waste generation at project level in new building construction, not demolition. These studies concern C\&D waste after it has been generated. In contrast, Kleemann et al. (2016) introduced a method for determining a building's material composition and future demolition waste. Moreover, various reduction, reuse, and recycling strategies (Peng et al., 1997), and the more proactive deconstruction strategy (Dantata et al., 2005), have been introduced to manage and minimize DWG.

Previous studies have reported that DWG is determined by a building's endogenous factors such as age (Poon, 1997), type (Wang et al., 2004), geometrical characteristics (Wang et al., 2004; Shi and $\mathrm{Xu}, 2006$ ), structure (e.g. steel, precast concrete, or brick) (Poon et al., 2001), or construction technologies used (e.g. prefabrication, or cast in-situ) (Jaillon et al., 2009). It is also known that DWG is influenced by exogenous factors such as demolition technologies (e.g. deconstruction, wrecking ball, or implosion) (Kibert et al., 2000, Kourmpanis et al, 2008; Poon et al, 2004), duration of demolition (Yuan et al., 2011), surroundings (Hendriks and Janssen, 2001), and constructors' C\&D waste management capability (Mcdonald and Smithers, 1998). However, in-depth, accurate understanding of DWG, in particular relating to these endogenous and exogenous factors, is lacking.

The insufficiency in understanding DWG may be attributable to the erratic and poor quality data available for research. Data collection methods adopted by previous C\&D waste management studies are diverse and include: direct observation (Poon, et al., 2001; Formoso et al., 2002), 
questionnaire survey (McGregor, et al. 1993; Wang et al., 2010), direct measurement (Bossink and Brouwers, 1996; Lau et al., 2008; Wu et al., 2014), interviews (Treloar et al. 2003; Tam et al., 2007); and tape measurement and truck load records (Skoyles, 1976). However, in real-life practice, when a demolition project is completed, construction companies are unable to provide relative accurate data because contractors are not obliged to record and report the qualitative and quantitative characteristics of the waste generated (Fatta et al., 2003). Most previous studies thus adopted sampling and ethnographic methods during construction or demolition processes. Although using objective methods, these studies had a relatively small sample or sampled relatively small sites due to the difficulties involved in conducting a full coverage survey (Katz and Baum, 2011; Lu et al., 2011). Existing DWG studies are thus inherently limited by their inability of accounting for the totality and accuracy of waste generation data throughout the demolition process.

This study is aiming to examine endogenous and exogenous factors that influence DWG at a project level by making use of a big dataset that has recently become available in Hong Kong's active construction sector. Owing to the Construction Waste Disposal Charging Scheme (CWDCS) conducted for C\&D waste management by Hong Kong Environmental Protection Department (HKEPD) (2005), this dataset records waste generation details for all sorts of projects including new builds, infrastructure, maintenance, and demolition. The more comprehensive picture provided by this big data can help support the introduction of proper DWG-minimizing interventions such as strategic plans, policies, research, and other managerial actions. This rest of the paper is divided into four main sections subsequent to this introductory section. Section 2 is a critical assessment of the existing studies on potential factors influencing DWG. Section 3 delineates the methodology, and the analyses and results are presented in Section 4. Section 5 discusses the results and Section 6 concludes the study.

\section{Factors affecting waste generation in building demolition}

A large number of factors influencing demolition waste generation (DWG) were mentioned by relevant regulations and previous studies. In Hong Kong, the Code of Practice (CoP) for Demolition of Buildings was published in 1998 and updated in 2004. It defines demolition as dismantling, razing, destroying or wrecking any building or structure or any part thereof by a pre-planned and controlled method (HKBD, 2004). The CoP considers the prevailing building structures in Hong Kong, i.e. high-rise concrete composite buildings, and other special buildings such as precast and pre-stressed concrete structures. It emphasizes a philosophy of planning (especially asbestos abatement, and removal of hazardous or regulated materials), precautionary measures (e.g. hoarding, scaffolding, and protecting traffic), operation, and close supervision and inspection. Further, on-site sorting of demolition waste is strongly recommended by the CoP, and the effectiveness of this practice has been examined by Poon et al. (2001) and Lu and Tam (2013). Recyclability of demolition waste, which depends on on-site separation and on-site reuse, is crucial to the amount of waste ultimately sent to waste receiving facilities. The separability 
and reusability of demolition waste are related to the endogenous factors of the building, which thus are investigated in details in this study.

Different demolition methods (e.g. top-down using manual methods or machines, use of hydraulic crushers with a long boom arm, use of a wrecking ball, implosion) and their associated practices are introduced in the CoP (HKBD, 2004). A 'selective demolition' method should be adopted as far as practicable; this involves demolition and removal of waste in stages according to category of waste, with the goal of facilitating recycling (HKBD, 2004). Implosion may be adopted when the aim is to expedite building demolition, for example when the land is to be redeveloped, or when other demolition methods are unsuitable due to the nature of a structure. Some parts of a building (e.g. metal members, glass, and non-load bearing partitions) can be removed during the implosion preparation stage, but the rest of the building will likely end up as demolition waste comprising a mixture of inert and non-inert materials not conducive to segregation, reuse, or recycling. In some extreme cases, entire buildings become waste (Wang et al., 2004). Deconstruction, in contrast, is a less wasteful method of demolition. It can be considered as a reversal of the construction process; buildings are systematically taken apart. This allows building materials to be kept intact as they are separated, making them easier to reuse and recycle. Some recyclable materials with strong markets or high disposal costs, like metals, heavy timber, gypsum drywall and concrete, are salvaged. In some exemplary cases, no demolition waste is generated at all. However, deconstruction is more expensive, labor-intensive, and time-consuming than other demolition methods, but can be more economically competitive if the costs and salvage value are well controlled (Dantata et al., 2005).Therefore, demolition method is a factor that is attributable to DWG.

Endogenous building characteristics are also crucial factors influencing DWG. Gross floor area (GFA) is a representative geometrical characteristic, and its correlation with DWG has been demonstrated in many previous studies (Poon, 1997; Poon et al., 2001; Lu et al., 2011). The methods applied in Poon (1997) and Poon et al. (2001) indicate that total waste generation amount is closely linked to GFA in both construction and demolition waste generation. According to Solís-Guzmán et al. (2009) conducted in Spain, the average DWG per $\mathrm{m}^{2}$ is 1.2676 $\mathrm{m}^{3}$. The number of floors in a building can be considered a proxy for GFA if this data is more attainable (Kern et al., 2015). Building usage (e.g., residential or commercial) has been considered as a factor affecting building compactness and thereby influencing total DWG amount (Poon et al., 2001; Banias et al., 2011). Regarding building usage details, different proportions of element types (e.g., floor, beam, door, wall, reinforcement, column, and window) and construction materials can result in different total DWG amounts (Cheng and Ma, 2013). Previous studies (e.g. Andersen et al., 2007; Bergsdal et al., 2007; Bohne et al., 2008; Seo and Hwang, 1999; Lu et al., 2016a) have also reported that building location is a factor influencing DWG. In addition, disparities between public and private sector activities have been identified in previous studies on C\&D waste generation (Poon et al., 2003; Lu et al., 2016b). 
DWG relates to not only characteristics of the demolition method but also waste management practice adopted by the demolition contractors (Poon et al., 2001; Lu and Tam, 2013). Emphasizing C\&D waste management is to avoid too much waste generation or even to achieve the goal of zero waste, but this goal is correlated with time and cost (Dantata et al., 2005; Lauritezen and Hahn, 1992; Poon et al., 2001; Yuan et al., 2011).It is known that the factors mentioned above are correlated with DWG of buildings, but the above studies have failed to demonstrate the extent of this correlation using convincing empirical evidence. C\&D waste is easy to see and relatively easy to measure ( $\mathrm{Lu}$ and Tam, 2013), so empirical research methods such as tape measurement and truck load records are often preferred. However, owing to rapid on-going demolition process and the temporary nature of projects, empirical data relating to DWG is not always accessible and recorded. As a result, previous studies have been critiqued as having only a relatively small sample or having sampled relatively small sites (e.g., Lu et al., 2011; Katz and Baum, 2011; Dahlbo et al., 2015). This study provides a novel approach, using big data to discover a full scope of DWG with several factors examined using available data concerning demolition projects.

\section{Big data applied to $C \& D$ waste management}

The three defining characteristics of big data are volume, variety, and velocity, or the three "Vs" (Laney, 2001; Zikopoulos and Eaton, 2011). Volume refers to quantity of terabytes, records, transactions, tables, or files; velocity finds expression in batch, near time, real time and streams; and variety means the data can be structured, unstructured, semi-structured or a combination thereof (Russom, 2011). Big data is used to create a new form of value in life, work, science and industry by planning and forecasting markets, organizations, and relationships between people; therefore, the hidden value that could be revealed by big data is highlighted as the fourth "V" (Mayer-Schönberger and Cukier, 2013; Gantz and Reinsel, 2011). Companies can leverage big data to create values such as adapting their products and services to better meet customer needs, optimize operations and infrastructure, and find new sources of revenue (EY, 2014). The value of big data can also be found in innovation, competition and productivity (Manyika et al., 2011; Gobble, 2013), and in many research disciplines, including biology (Howe et al., 2008), medical science (Murdoch and Detsky, 2013), ecological science (Hampton et al., 2013) and business (Chen et al., 2012) by analyzing the patterns based on the information generated. The big data in this study is daily generated from the waste disposal transaction recording system by HKEPD, and collated as well-structured datasets, with a total volume of over $500 \mathrm{MB}$ in CSV files.

There is a very limited but growing body of literature on big data in construction. For example, Renovation in Building (2014), a software company to provide solutions in the construction industry, has developed a big data platform that enables virtual planning of construction projects before and during construction works. In smart urbanization, big data, which is varied, fine-grained, indexical, dynamic and relational, enables real-time analysis of different systems as well as interconnection of data across systems providing a detailed view of relationships 
(Kitchin, 2014). In the area of C\&D waste management, Lu et al. (2015) relied on big data to estimate the quality of previous C\&D waste management, set benchmarks for management performance, and to raise suggestions for management improvement. Lu et al. (2016b) applied big data analytics in discovering differences in public and private sector C\&D waste management, found public sectors performed better than their private counterparts, and raised corresponding suggestions for policy-making. Studies by Lu et al. (2015) and Lu et al. (2016b) were based on the real transactional records of C\&D waste, and provided a full picture of the C\&D waste management status quo in Hong Kong. Bilal et al. (2016) also opined that big data analytics is an effective and advanced application in designing waste minimization. While big data are successfully applied to extracting the above values, this study is the first specifically applying big data in understanding DWG.

An advantage of big data compared with traditional sampling data is that it can offer a fuller picture of the subject domain under investigation (Lu et al., 2015). Research findings deriving from big data analytics can attribute to more accurate predictions, better decisions, and precise interventions in practical applications (McAfee et al., 2012). This echoes the view of Mayer-Schönberger and Cukier (2013) that big data "refers to things one can do at a large scale that cannot be done at a smaller one, to extract new insights or create new forms of value, in ways that change markets, organizations, the relationship between citizens and governments, and more". With big data, traditional theory driven research can become data driven. For example, Howe et al. (2008) assert that big data analytics will become the mainstream of the future biology research. Data mining as a discipline has developed to meet the urgent need to automatically discover valuable information within a large data collection and to transform it into organized knowledge (Han and Kamber, 2001). Frequent patterns, associations and correlations, classification and regression, clustering analysis and outlier analysis are patterns to mine in datasets (Han et al., 2011).

DWG is supposed to be impacted by many factors. While in the real life, demolition projects and the waste generation data are not easily accessible. Big data for DWG, if available, can be used to isolate the effects of the factors, and identify the ones that really matter to DWG. Complying to the Law of Large Numbers (LLN), the average of the results obtained from a large number of trials should tend to become convergent to a certain value as more trials are performed (Sen and Singer, 1994). This study identifies the factors that influences DWG that can be generalized from individual projects to reflect the prevailing demolition waste management picture of an economy. It can alleviate the many problems (e.g. limited sample size on demolition activities) that have arisen in previous studies of this kind and facilitate more robust research findings in order to provide a clearer understanding of DWG.

\section{Methodology}

\subsection{Description of the big data}


The big data applied in this study constitutes three databases as shown in Fig. 1. This big dataset used in this study is totally about 500MB in CSV file. The core "transaction records" database is composed of 6,383,850 C\&D waste transaction records from 2011 to 2015 generated under the Construction Waste Disposal Charging Scheme (CWDCS) launched by the Hong Kong Environment Protection Department (EPD) in 2006. Under this scheme, waste disposal facilities record information on every lorry load of $C \& D$ waste received from every construction/demolition site, including "Facility", "Date of transaction", "Vehicle No.", "Account No.", "Time in", "Time out", "Weight in", "Weight out", and "Net weight". "Facility" refers to the name of the government waste disposal facility for $C \& D$ waste belonging to one of the four types: public fill reception facilities, sorting facilities, landfills, and outlying island transfer facilities; "Date of transaction" is the date when the facility receives the lorry of C\&D waste; "Vehicle No." is the license plate number of the lorry carrying C\&D waste; The CWDCS also requires all contractors involved in C\&D activities including new builds, demolition, renovation and maintenance to open a billing account by assigning an "Account No."; "Time in" and "Time out" are when the lorry arrives and leaves the facility; "Weight in" and "Weight out" are the measurement of the total weight of the lorry when it arrives and leaves the facility; and "Net weight" is the total weight of the lorry of C\&D waste received by the facility.

For every billing account, C\&D works' information, including "Account", "Contract sum", "Site address", "Department", and "Construction type", is also recorded by the EPD. These accounts and their information form the "account information" database, which can be linked to the core database (i.e. "transaction records") where "Account No." (i.e. "Account") serves as the bridge to examine each facility's waste generation in detail. "Contract sum" is the project cost achieved in the construction contracts of the C\&D work; "Site address" is the detailed address of the construction site; "Department" is the sector in charge of the C\&D work, and only government departments are recorded; and "Construction type" is the type of the construction work (i.e. building, demolition, foundation, renovation, site formation, etc.).

Another database, "Demolition information" shown in Fig. 1 contains "Building type" of issued demolition work, which is from the tables for buildings for which building authority has issued demolition orders in the Monthly Digest of the Hong Kong Buildings Department. "Address of site" is the detailed site address for the demolition work. It serves as a bridge linking "Demolition information" and "Account information" by referring to the "Site address" in the latter database. 


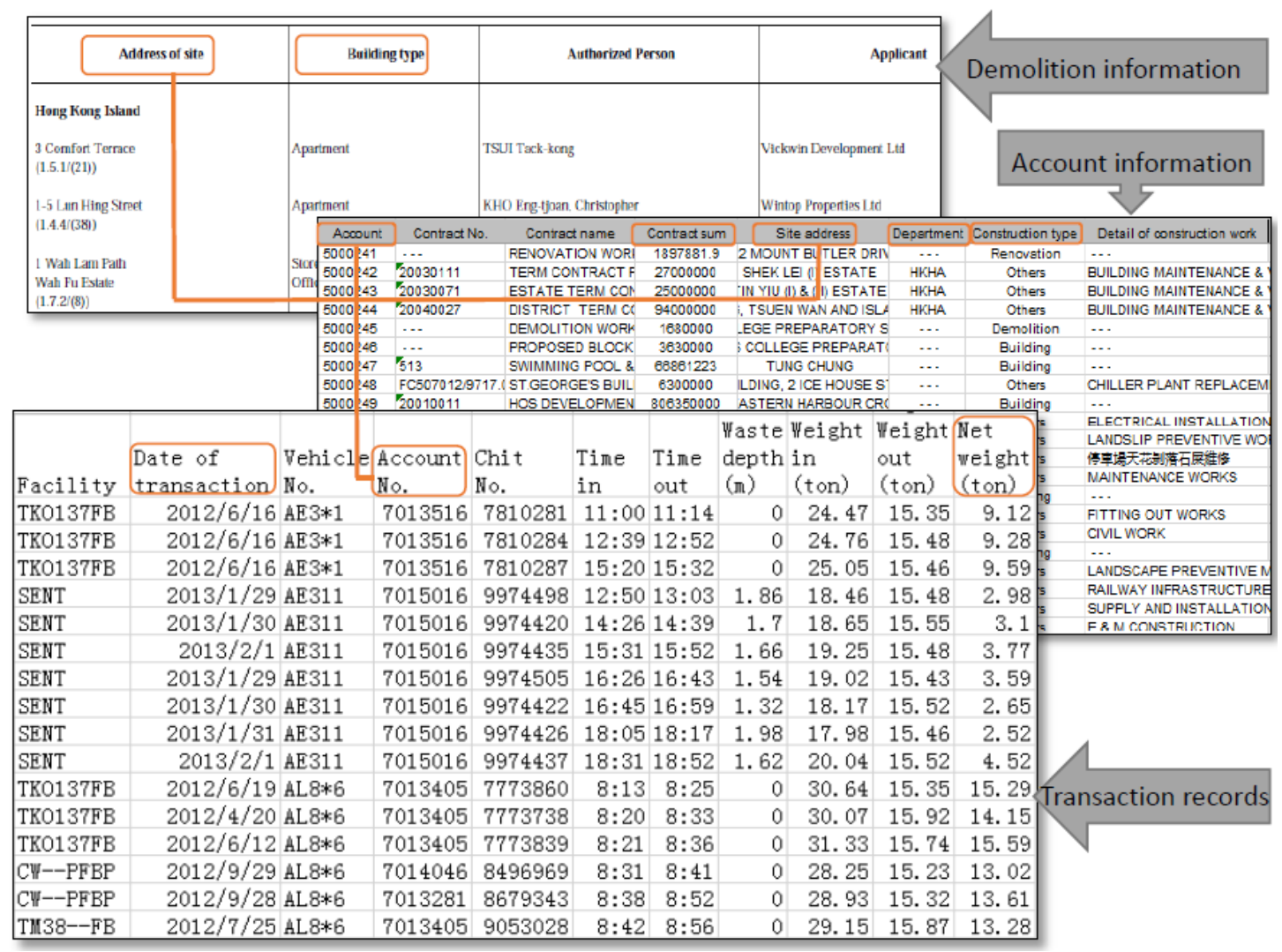

Fig. 1 Databases concerned with DWG in Hong Kong

\subsection{Data preparation}

Site address and account No. serve as bridges linking the three databases so as to reflect the whole DWG picture in Hong Kong. The variables that may correlate to DWG are identified and highlighted in Fig. 1. They are: contract sum, date of transaction, site address, department, and building type. The first four variables denote each demolition project's cost, duration, location development level, and public-private developer status. Demolition projects were first identified according to the construction type in "account information". While 892 demolition projects have been undertaken since enactment of the CWDCS in 2006, waste transaction records have only been collected since 2011. Therefore, projects were identified based on the following criteria:

(a) they must be demolition projects;

(b) the sum of the demolition weight for the account is not zero; and

(c) there is DWG between 10 Jan 2011 and any day before 21 Dec 2015.

As a result of this selection process, 422 demolition projects were selected for further analysis. They include 112,100 transaction records detailing DWG. While these transaction records number far less than the original 6,383,850, totally exceeding 500MB in CSV file, they still meet the volume of three "Vs" of big data because the main database consists of well-structured data frames, which are processed from scattered waste disposal records covering the full population under investigationFor every demolition project, in addition to weight sum, waste transaction duration is calculated based on transaction dates, the region where the site belongs to 
is identified, the building type is sorted, and the public-private nature of the client is identified. The data is then ready for correlation analyses in order to find out the factors influencing DWG.

\subsection{Data analysis}

First, pairwise correlation analysis is conducted to examine whether the following pairs of factors are correlated:

(a) contract sum and duration,

(b) weight and contract sum,

(c) weight and duration,

(d) weight and site region,

(e) weight and building type, and

(f) weight and public-private nature of the developer.

Contract sum denotes the price of the contract agreed between the contractors and clients, which can be regarded as demolition cost in this study; duration for a demolition project is the waste generation period, which can be regarded as the demolition duration considering the limited buffer area for demolition waste storage in Hong Kong; weight is the total waste amount finally sent to the waste receiving facilities for the demolition projects; site region is the region (i.e. Hong Kong Island [HK], Kowloon [KLN] or the New Territories [NT]) where the demolition site belongs to; building type is the usage of the demolished premise (i.e. civil \& Building service [civil\&BS], commercial, industrial, residential \& commercial [R\&C], residential or others); and public-private nature of the developer denote the sector that develops the project involving the demolition work (i.e. public or private sector).

After understanding the above-listed pairwise correlations, regression is conducted to examine how independent factors (i.e. site region, building type and public-private nature of the developer) collectively impact on DWG in individual projects. Regression is a classical data analysis approach for examining the influence factors for a result (Draper et al., 1966). Generation of construction waste in relation to economic activity has been well demonstrated by the EEA (1999) using the linear regression approach. Therefore, this study adopts regression to identify the factors influencing DWG. All analyses were performed in $R$, open-source data analysis and graphics software. It is expected that the big data, encompassing the detailed DWG of a full population (i.e. all completed demolition projects during the period), will allow more robust statistical analyses. Bearing in mind that "correlation does not imply causation", the researchers also interrogate the data and other data sources for particular demolition projects in order to understand the actual causal effects between factors.

\section{Results}

\subsection{Correlations between contract sum, duration and waste weight}

The distributions of contract sum and $\ln (\ln$ (contract sum) are roughly plotted in Fig. 2. The 
former is too skewed thus the latter is made for a similar normal distribution. The values of $\ln (\ln ($ contract sum $))$ are employed in the afterward regression analysis as it is better for the variables to be similar to a normal distribution in the linear regression. The distributions of demolition duration and $\ln$ (duration) are plotted in Fig. 3. The former is too skewed thus the latter is made for a similar normal distribution for the afterward regression analysis. The same is for the distributions of waste weight and $\ln$ (waste weight), which are shown in Fig. 4, and $\ln$ (waste weight) is used for the regression analysis..
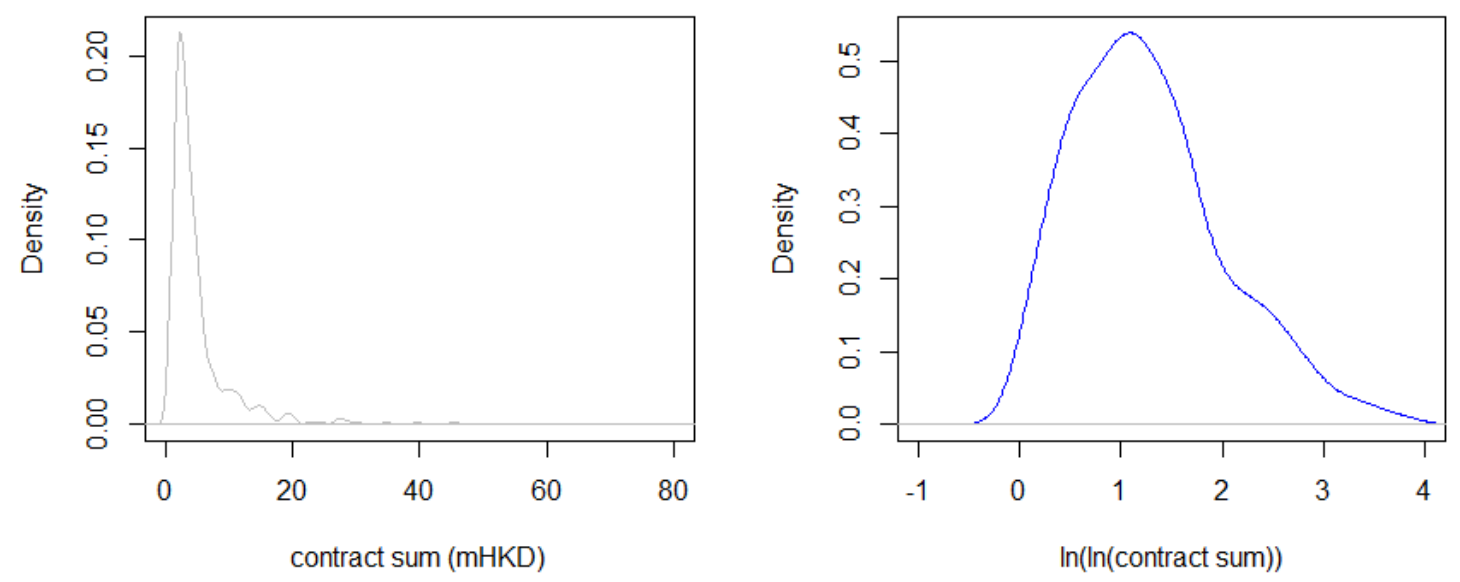

Fig. 2 The distribution of contract sums and $\ln (\ln ($ contract sum $)) \mathrm{s}$
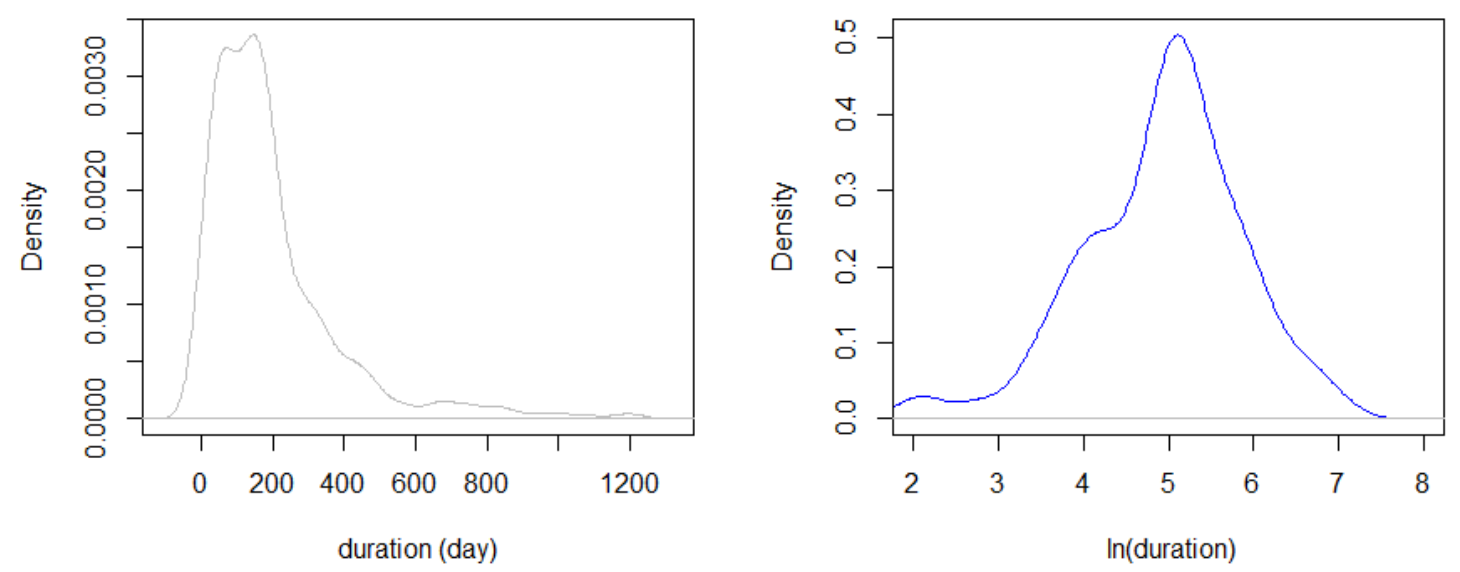

Fig. 3 The distribution of durations and $\ln ($ duration)s
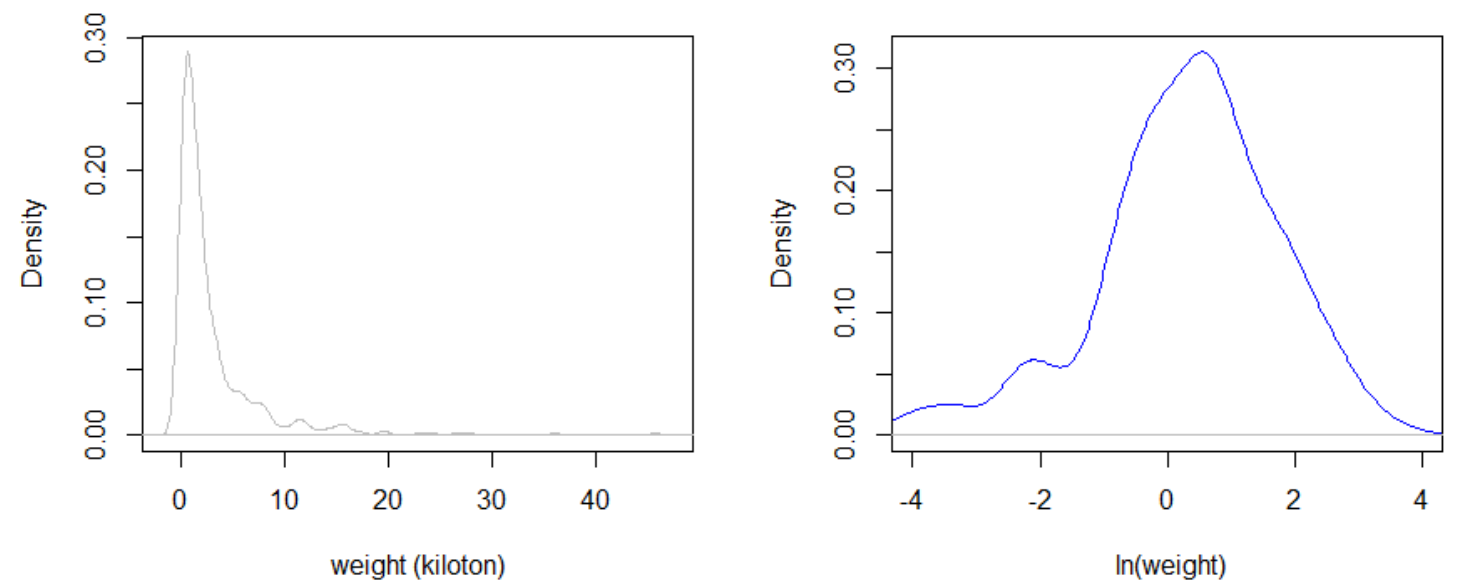

Fig. 4 The distribution of waste weights and $\ln ($ weight)s 
To investigate how they are correlated, the scattered plots of pairwise combinations of the variables are demonstrated in Figs. 5, 6 and 7. Readers of this paper are reminded that there are $C_{3}^{2}=3$ pairs of correlations to be examined given the three potential influence factors. It can be seen from Figs. 5, 6 and 7 that there appears to be a positive correlation between $\ln (\ln$ (contract sum)), $\ln$ (duration) and $\ln$ (weight) for the 422 demolition projects. To some extent, this observation can be explained with the trend lines and the corresponding equations in Figs. 5, 6 and 7. This observation is consequently confirmed by statistical analyses. The $R$ squares and $P$-values of the linear regressions for the combinations of the variables are listed in Table 1 . The $R$ squares of the trend lines, which are statistical measures of how close the data are to the fitted regression line, here fail to approach 1 , which indicates perfect fitting. The equations in these figures are thus lack of representativeness to reflect correlations, (a), (b) and (c) owing to the low $\mathrm{R}$ squares. If $\mathrm{R}$ squares approach 1 , when either duration or contract sum is given, demolition waste weight can be estimated using the equations. Nevertheless, the higher the $\mathrm{P}$-values are, the less the correlation significances are between contract sum, duration and waste weight of a demolition work. The $P$-values listed in Table 1 are far less than 0.001 , which indicate the possibilities to receive the null hypothesis that there is no relationship between the tested variables are all less than 0.001 for the three pairs of correlations.

The extremely low $P$-values indicate a very strong relationship between contract sum, duration, and waste weight of demolition projects. The data of Hong Kong shows contract sum of the demolition work, demolition duration, and demolition waste weight are positively correlated in a general pattern. Therefore, DWG measured by weight is significantly influence by buildings' exogenous factors such as contract sum and the duration of the demolition work, which is also effective in other cities because contract sum and demolition duration are generic characteristics for every demolition project. However, the low $\mathrm{R}$ squares of the equations of the trend lines indicate there might be factors (e.g. demolition method, geometrical characteristics, building usage, and building location as mentioned in Section 2) influencing the DWG other than contract sum and demolition duration.

Table $1 \mathrm{R}$ squares and P-values of combinations of $\ln (\ln ($ contract sum $)), \ln ($ duration $)$ and $\ln$ (weight)

\begin{tabular}{llll}
\hline Combination of variables & R square & P-value & $\begin{array}{l}\text { Correlation } \\
\text { significance }\end{array}$ \\
\hline $\ln (\ln ($ contract $\operatorname{sum}))$ and $\ln ($ duration $)$ & 0.0926 & $7.97 \times 10^{-12}$ & Significant \\
\hline $\ln ($ weight $)$ and $\ln ($ contract sum $)$ & 0.1562 & $6.25 \times 10^{-26}$ & Significant \\
\hline $\ln ($ weight $)$ and $\ln (\ln ($ duration$))$ & 0.2629 & $1.76 \times 10^{-12}$ & Significant \\
\hline
\end{tabular}




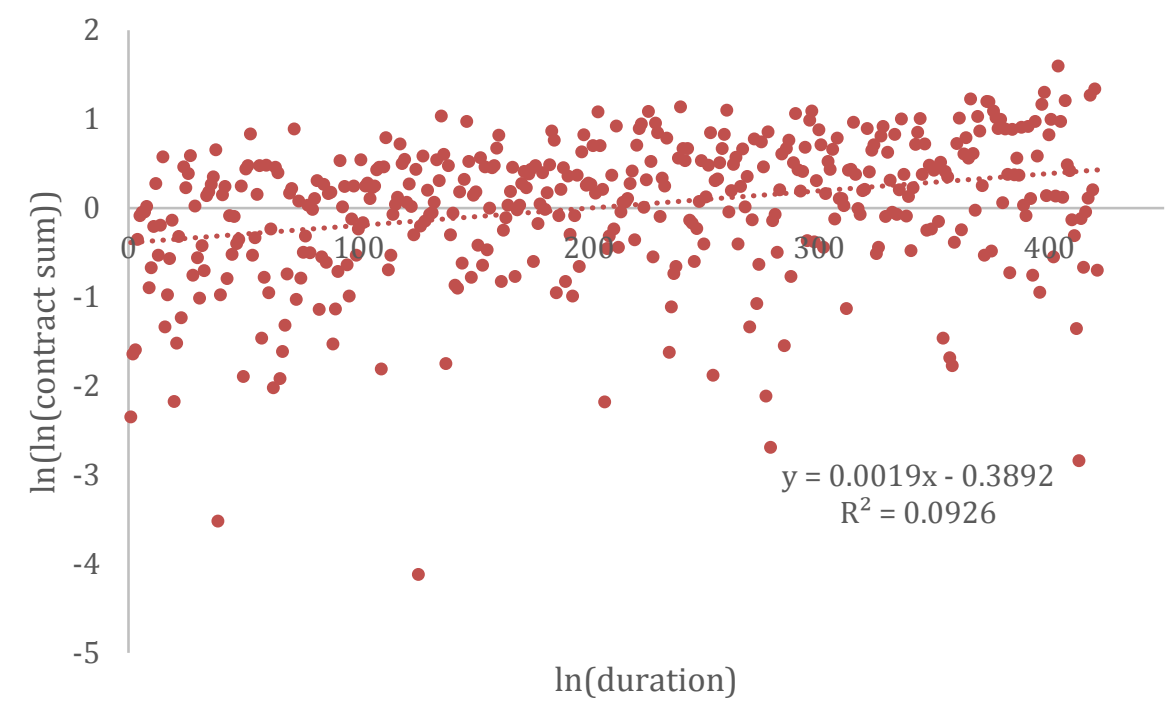

Fig. 5 Correlation between $\ln (\ln ($ contract sum $)$ and $\ln ($ duration $)$

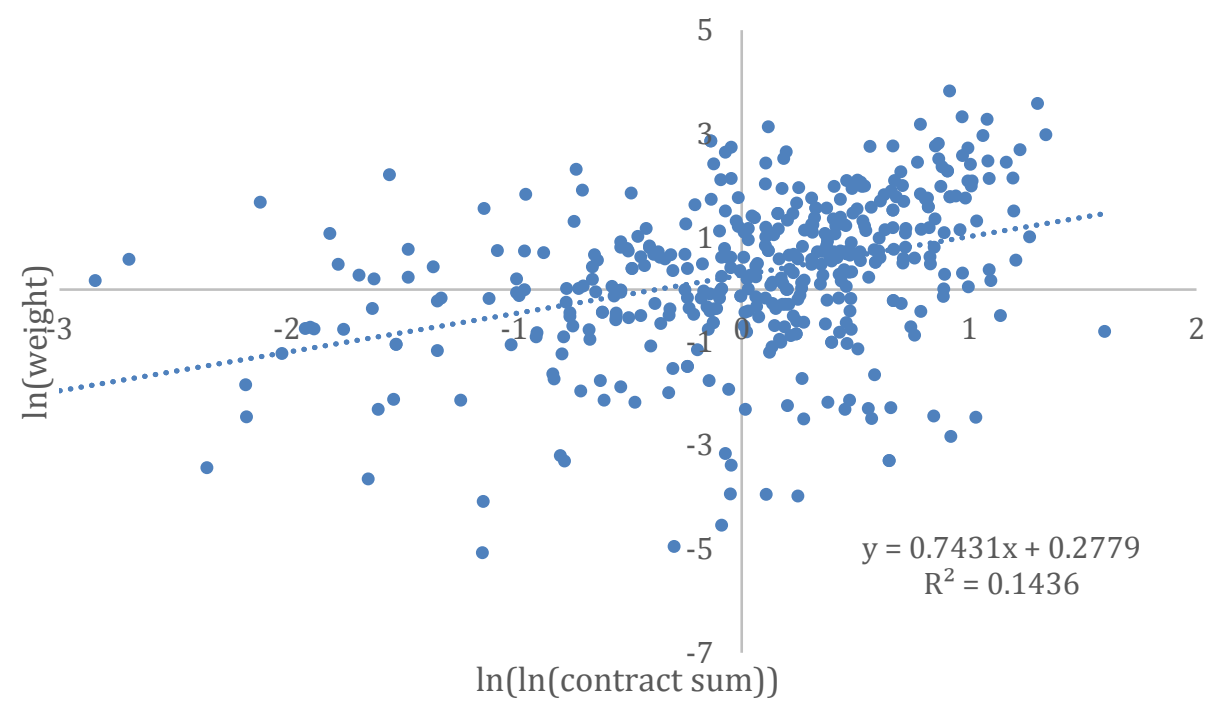

Fig. 6 Correlation between $\ln ($ weight $)$ and $\ln (\ln ($ contract sum $))$ 


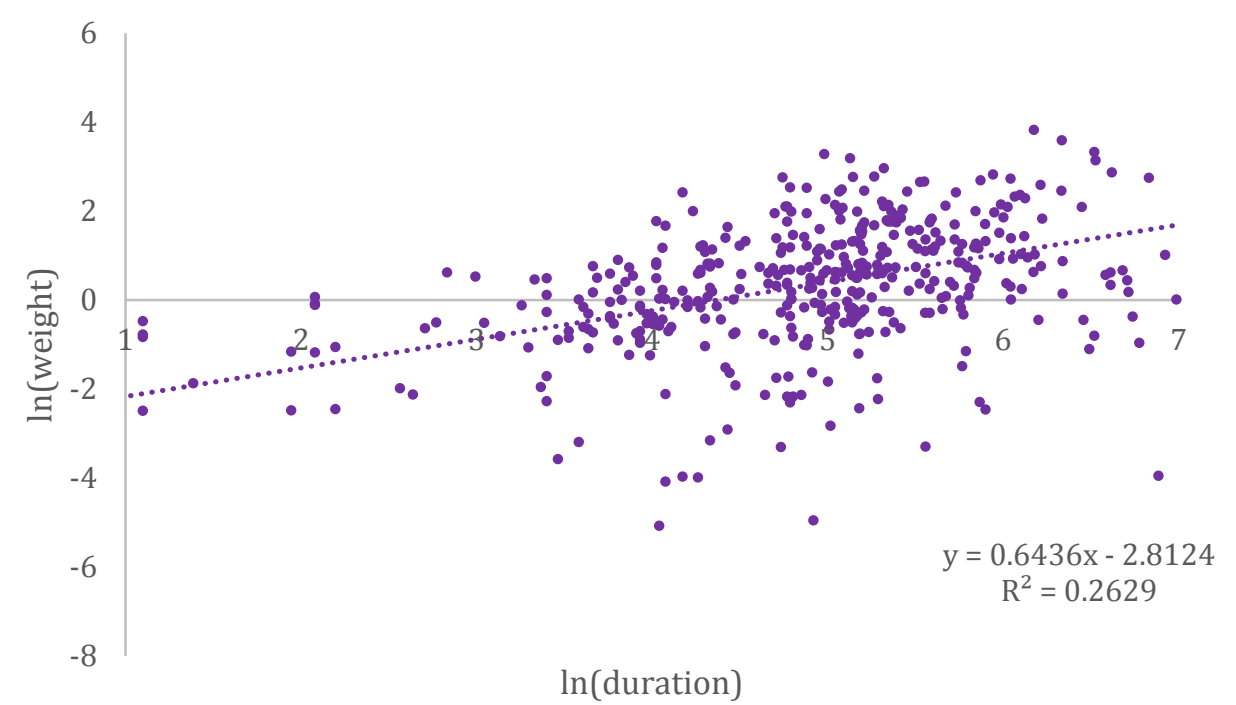

Fig. 7 Correlation between $\ln ($ weight $)$ and $\ln ($ duration $)$

\subsection{Multiple linear regression with project characteristics}

Firstly, it is hypothesized that DWG will be impacted by region in which the project is located. Hong Kong is divided into three regions; HK, KLN and NT. Of the 422 demolition projects, 202 projects are located in HK, 160 in KLN, and 60 in NT. The $\ln$ (weight)s of projects in the three regions are plotted in Fig. 8. It can be seen that projects located in NT generate less demolition waste than projects in HK or KLN. Linear regression is performed with $\ln$ (weight) as response variable and regions as explanatory variables in $R$. The result is shown in Table 2 . The $P$-values for project characteristics here also mean the possibility of accepting the null hypothesis that the project characteristic have no effect on $\ln$ (weight). Therefore, whether a demolition project is located in NT or not $\left(P\right.$-value $\left.=6.19 \times 10^{-9}\right)$ is indeed a factor strongly affecting $\ln$ (weight). Therefore, the 422 projects can be divided into two regional groups, NT or HK\&KLN, for further analyses. To estimate the difference in DWG of NT and HK\&KLN projects, the medians of $\ln$ (weight)s and weights for projects in NT and HK\&KLN are calculated and shown in Table 3. It appears from this analysis that demolition projects on Hong Kong Island and in Kowloon are much more wasteful than those in the New Territories. 


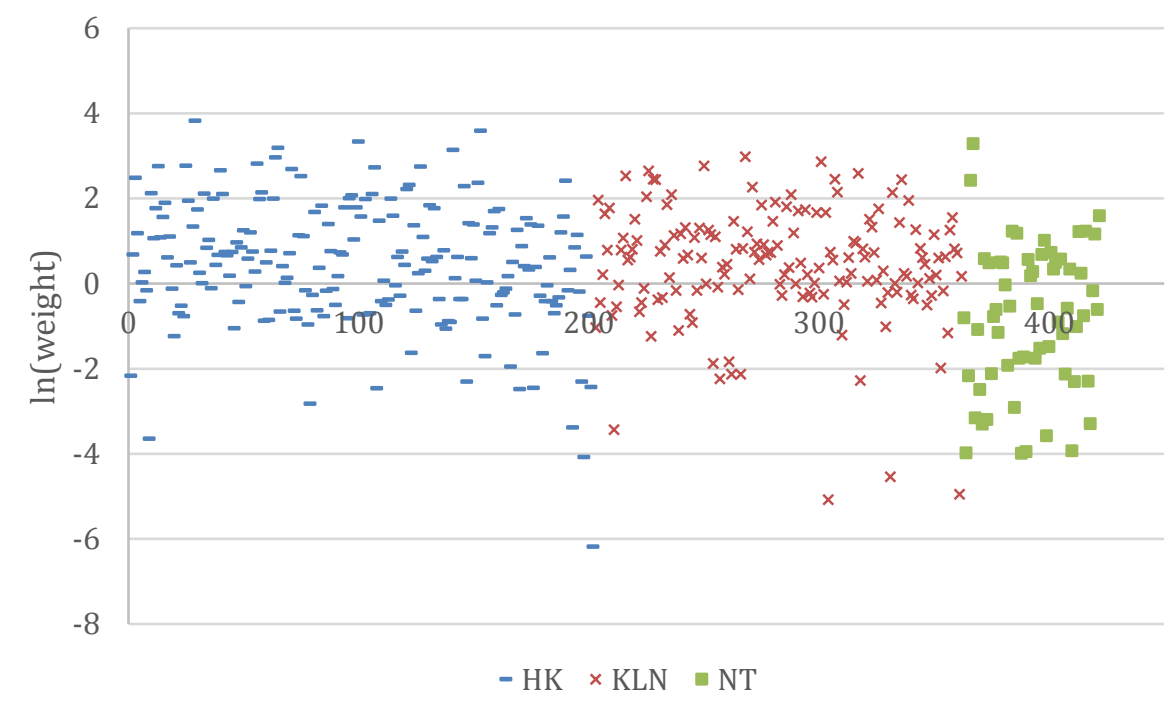

Fig. 8 The $\ln$ (weight)s of projects in HK, KLN and NT

Table $2 \mathrm{P}$-values of the linear regression with region as explanatory variables

\begin{tabular}{lll}
\hline Variable & P-value & Controlling significance \\
\hline NT or HK\&KLN & $6.19 \times 10^{-9}$ & Significant \\
\hline KLN or NT\&HK & 0.925 & Not significant \\
\hline
\end{tabular}

Table 3 The medians of $\ln$ (weight)s and weights for projects in NT and HK\&KLN

\begin{tabular}{lll}
\hline Median & NT & HK\&KLN \\
\hline $\ln$ (weight) & -0.86 & 0.58 \\
\hline weight (kiloton) & 0.50 & 1.79 \\
\hline
\end{tabular}

Building types of the 422 demolition projects are identified mainly based on the Monthly Digests of the Government Buildings Department of Hong Kong and include apartment, residence, commercial, industrial, $\mathrm{R} \& \mathrm{C}$, garden features, recreational facilities, playground, park, and BS. This study divides these building types into six categories based on their similarities: civil\&BS, commercial, industrial, $\mathrm{R} \& \mathrm{C}$, residential and others. When $\mathrm{n}$ categories are tested as an influence factor, $n-1$ explanatory variables sufficient to represent this factor should be applied in regressions. Therefore, five explanatory variables listed in Table 4 are randomly selected in $R$ for regressing the building categories as a DWG influence factor. The $\ln$ (weight)s of the six building categories are plotted in Fig. 9. Differences in the $\ln$ (weight)s between the categories can be observed. In addition, linear regression is performed in $R$, and the $P$-values are shown in Table 4 . The $P$-values show each category significantly impacts on $\ln$ (weight), which means there are statistically significant $\ln$ (weight) differences between these categories. The medians of $\ln$ (weight)s and weights for projects belonging to different categories are calculated and shown in Table 5. The result shows that the largest waste amount (3.63 kilotons) resulted from industrial building demolition, civil\&BS demolition work generated the least waste at 0.11 
kilotons, and commercial, residential, and $\mathrm{R} \& \mathrm{C}$ building demolition generated a waste amount of 1 to 2 kilotons.

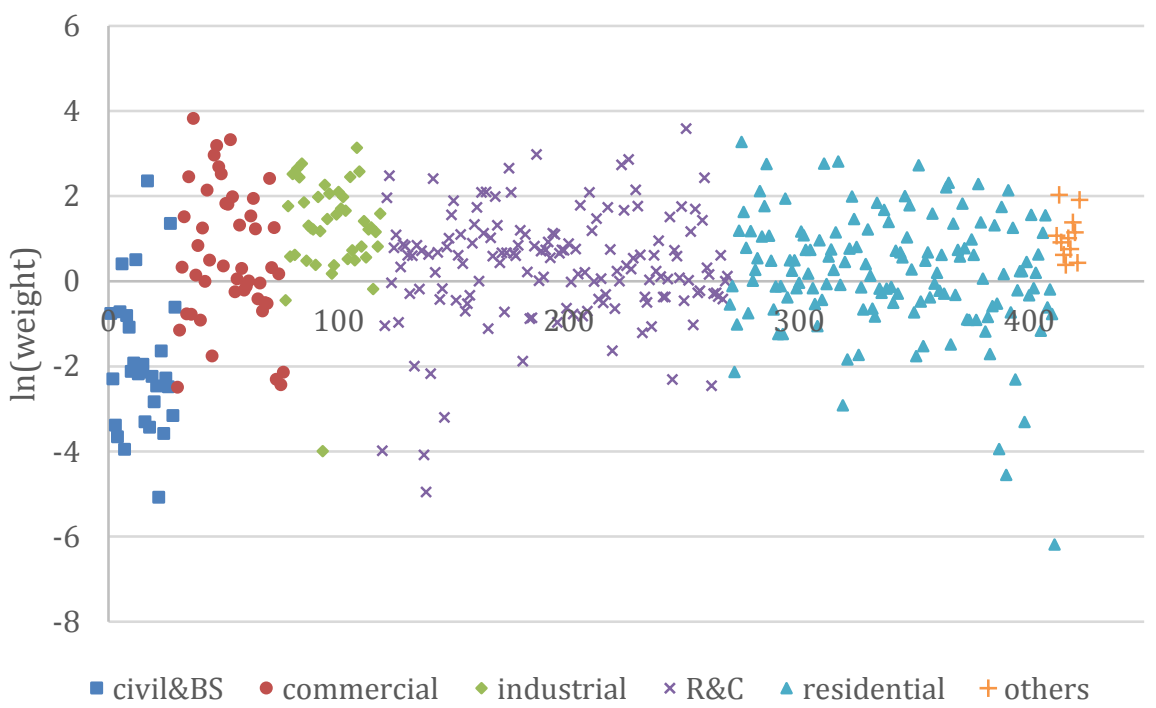

Fig. 9 The $\ln$ (weight) of projects by building categories

Table $4 \mathrm{P}$-values of the linear regression with building categories as explanatory variables

\begin{tabular}{lll}
\hline Variable & P-value & $\begin{array}{l}\text { Controlling } \\
\text { significance }\end{array}$ \\
\hline Commercial or not & $1.50 \times 10^{-13}$ & Significant \\
\hline Industrial or not & $<2 \times 10^{-16}$ & Significant \\
\hline R\&C or not & $6.72 \times 10^{-15}$ & Significant \\
\hline Residential or not & $3.35 \times 10^{-13}$ & Significant \\
\hline Others or not & $2.26 \times 10^{-9}$ & Significant \\
\hline
\end{tabular}

Table 5 The medians of $\ln$ (weight)s and weights for projects by building categories

\begin{tabular}{lllllll}
\hline Median & Civil\&BS & Commercial & Industrial & R\&C & Residential & Others \\
\hline $\ln ($ weight $)$ & -2.17 & 0.32 & 1.29 & 0.55 & 0.24 & 1.01 \\
\hline $\begin{array}{l}\text { weight } \\
\text { (kiloton) }\end{array}$ & 0.11 & 1.38 & 3.63 & 1.73 & 1.27 & 2.75 \\
\hline
\end{tabular}

Some demolition permits, particularly in the case of institutional buildings, are requested by public clients such as the Civil Engineering and Development Department, the Lands Department, the Architectural Service Department, and the Hong Kong Housing Authority, while others are requested by private developers. Among the 422 demolition projects, 387 were developed by a private sector entity and 35 by government departments. Their $\ln$ (weight)s are plotted in Fig. 10, where each dot represents a demolition project. It can be seen from Fig. 10 that private sector projects seem to result in higher DWG than public sector projects. Interestingly, $\mathrm{Lu}$ et al. (2016) discovered a notable C\&D waste management performance disparity between the public and private sectors in Hong Kong, with contractors performing 
better in managing both inert and non-inert waste in public projects than in private projects. The public-private nature of projects is regressed as an explanatory variable, and the $p$-value is $1.64 \times 10^{-12}$, which means that $\ln$ (weight) is highly related to the project's public-private nature. The medians of $\ln$ (weight)s and weights for projects belonging to different sectors are calculated and shown in Table 6 . Waste generation by private projects (1.60 kilotons) is nearly 10 times that of public ones ( 0.18 kilotons).

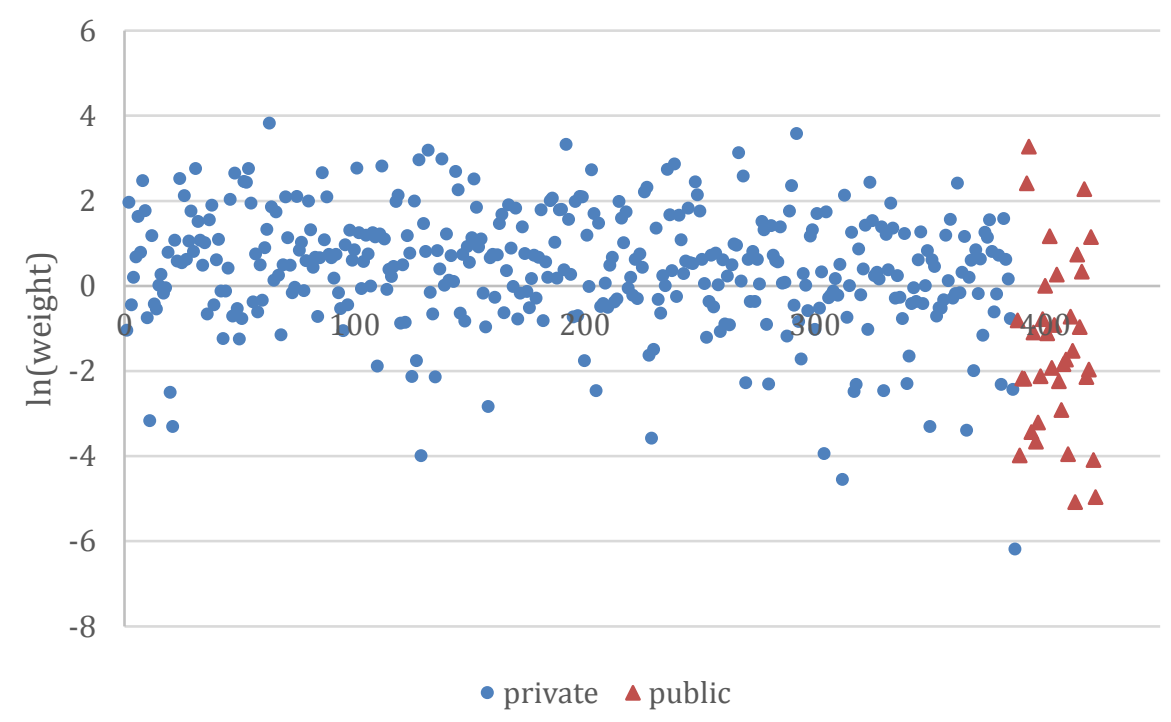

Fig. 10 The $\ln$ (weight) of projects by public-private nature of developers

Table 6 The medians of $\ln ($ weight)s and weights for projects developed by public and private sectors

\begin{tabular}{lll}
\hline Median & Public & Private \\
\hline $\ln ($ weight $)$ & -1.73 & 0.53 \\
\hline weight (kiloton) & 0.18 & 1.69 \\
\hline
\end{tabular}

Multiple linear regression is performed with region, building category, and public-private nature of developer as explanatory variables and $\ln$ (weight) as the response variable. Table 7 shows the result of the multiple linear regression. The adjusted $R$ square is 0.2655 , which means the regression is not perfectly fitted. The $p$-value of the regression is $<2.2 \times 10^{-16}$, which means all three factors significantly impact on $\ln$ (weight). Although a project's DWG is not purely dependent on its region, building category, and public-private nature, it is significantly influenced by these three factors. Moreover, every variable in the regression is significantly controlling for the other variables, meaning every explanatory variable is effective in impacting $\ln$ (weight) when other variables are controlled.

Table 7 The result of multiple linear regression with region, building category, and public-private nature of the developer as explanatory variables

\begin{tabular}{|c|c|c|c|c|}
\hline Variable & P-value & Significance & $\mathrm{R}$ square & P-value \\
\hline NT/HK\&KLN & $8.75 \times 10^{-7}$ & Significant & & \\
\hline
\end{tabular}




\begin{tabular}{lll|l|l}
\hline Commercial or not & $2.66 \times 10^{-8}$ & Significant & \multirow{3}{*}{0.27} & \\
\cline { 1 - 2 } Industrial or not & $1.24 \times 10^{-14}$ & Significant & \multirow{2}{*}{$<2.2 \times 10^{-16}$} \\
\cline { 1 - 3 } Others or not & $9.86 \times 10^{-7}$ & Significant & & \\
\cline { 1 - 3 } R\&C or not & $1.03 \times 10^{-7}$ & Significant & & \\
\cline { 1 - 3 } Residential or not & $1.26 \times 10^{-7}$ & Significant & & \\
\cline { 1 - 3 } Public/Private & $8.02 \times 10^{-4}$ & Significant & & \\
\hline
\end{tabular}

\section{Discussions}

\subsection{Demolition waste generation (DWG) and buildings' indigenous factors}

As evidenced by the extremely small $P$-values, this research strongly asserts that DWG measured by weight is significantly affected by a building's indigenous factors such as geographical location, usage/category, and public-private nature. The big data analytics reveal that the demolition waste amount disposed of by projects located in Hong Kong (HK) and Kowloon (KLN) is generally three to four times higher than that of New Territories (NT) projects.

Before the 1970s, most residential, commercial and industrial activities were concentrated on Hong Kong Island and the Kowloon peninsula, while the New Territories were not well developed (Li et al., 2004). At present, according to the Hong Kong in Figures by Census and Statistics Department (C\&SD) (2016), HK and KLN have been developing into high-density locations with a population density of 15,740 per $\mathrm{km}^{2}$ for the former and 47,040 per $\mathrm{km}^{2}$ for the latter, while NT has only developed to a population density of 4,020 per $\mathrm{km}^{2}$. Amid HK and KLN's urban decay, new buildings are developed on demolition sites; indeed, HK and KLN had a total of 362 demolition projects over the period studied, while the NT had only 60. Representative buildings in the developed areas of HK and KLN are modern, with a standard design and more than six floors; those in the NT are old village houses, often with just one or two storeys. Redevelopment in KLN and HK is more urgent, thus less attention is paid to waste management as it is often labor-intensive and time-consuming. From Fig. 11, it can be seen the confined land areas of KLN and HK (i.e. $80.7 \mathrm{~km}^{2}$ and $46.9 \mathrm{~km}^{2}$ ), which are around 10 and 20 times less than that of NT (i.e. $978.1 \mathrm{~km}^{2}$ ) are possibly another factor explaining the urgent need of redevelopment. HK and KLN are the two main regions for DWG in Hong Kong, and government should therefore strategically handle them with more caution. 


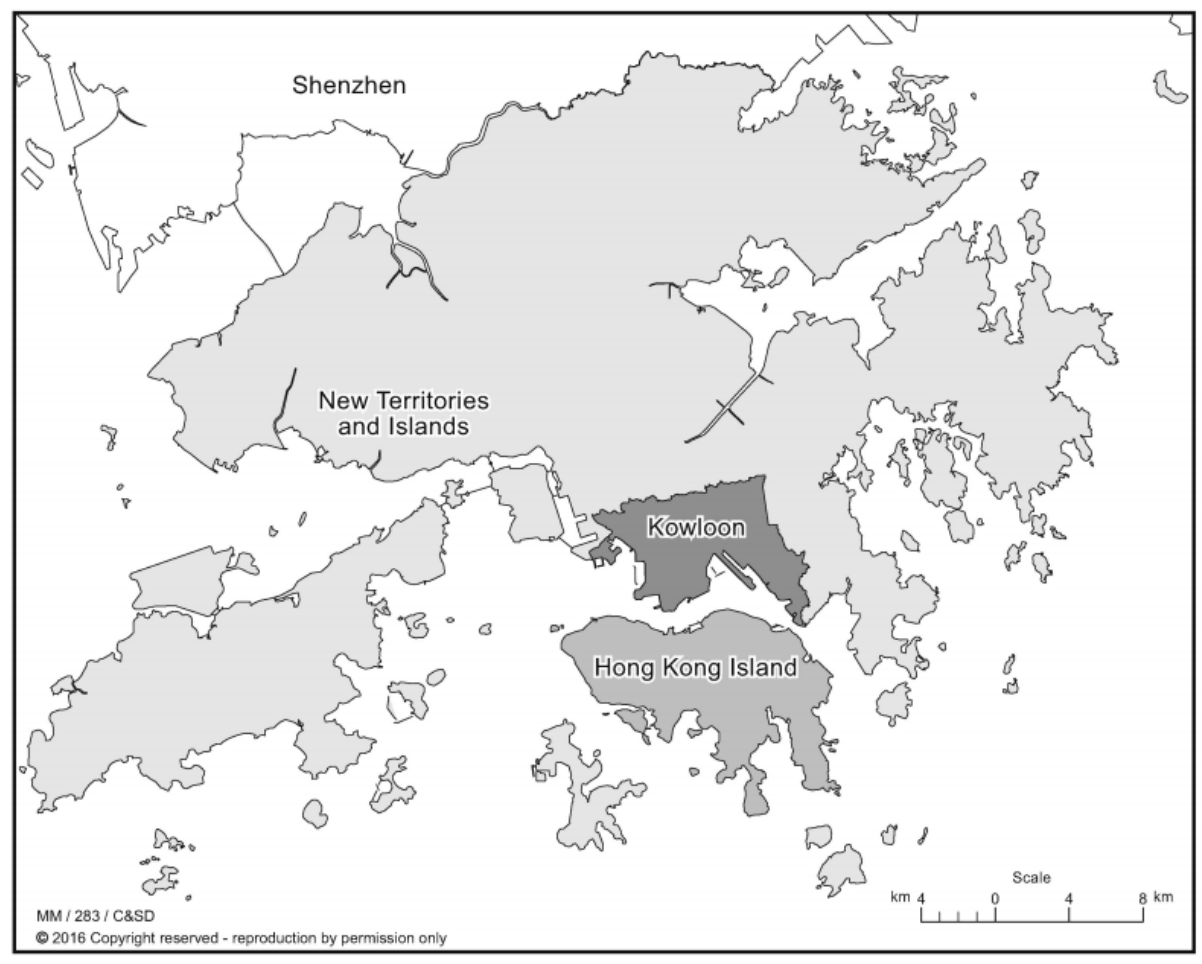

Fig. 11 Map of Hong Kong (C\&SD, 2016)

This study also found that building usage/category has a great influence on DWG. Certainly, different structures and building technologies were adopted appropriately when the buildings were designed and erected for different uses. Notably, DWG from industrial buildings is far higher than that of other building categories. Hong Kong Legislative Council (2011) pointed out most of Hong Kong's industrial buildings are located in urban areas and furnished with large floor plates, high ceilings, strong floor loadings, wide corridors and large lifts for the manufacturing industry. As a result of these characteristics, these buildings generate more waste material upon demolition. Also notable is that the waste generated by demolition of residential/commercial ( $\mathrm{R} \& \mathrm{C}$ ) complex buildings is higher than that of single function (either residential or commercial) buildings; possibly because $\mathrm{R} \& \mathrm{C}$ complex buildings have a higher plot ratio and more GFA than simple residential or commercial buildings. Civil and building services (BS) demolition works generate the least amount of waste. This is because the civil projects in this study including pump stations, public toilets, playgrounds and swimming pools, and BS facilities such as lifts, electromechanical systems, and air conditioning systems are generally small in scale.

It is somewhat surprising to find that the public-private nature of a demolition project has a statistically significant impact on DWG. General belief is that both sectors are under the governance of the same set of CWM-related regulations, and thus there should be no disparity between them in CWM performance. This study specifically compared DWG using five years' waste disposal records, discovering that the median waste weight for demolition projects conducted by private developers is about 10 times that of their public counterparts. The finding that the public sector performs better in demolition waste management than the private sector 
echoes that in Lu et al. (2016), which suggested that public projects are obligated to show leadership in environmental protection while private developers are motivated by profit. It is often said that Hong Kong's private construction sector is populated by "cowboys" and is "unmanageable". Indeed, it is no surprise that profit is the private sector's mantra in the world's freest economy for 22 years running. It is at the sector's discretion to make the commitment to C\&D waste management in conjunction with other considerations such as development costs and timing.

\subsection{Demolition waste generation (DWG) and buildings' exogenous factors}

This research confirmed that DWG measured by weight is significantly affected by buildings' exogenous factors such as contract sum and the duration of the demolition work. It is intuitive that the larger the amount of waste generation, the higher the demolition cost and contract sum will be. The big data validates this intuition, yet exceptions exist due to the dynamic relationship between these factors, which are also proved not dominant for each other in this study Proper financial investment could affect C\&D waste management performance (Mills et al., 2009), which means that sometimes a higher contract sum may lead to lower DWG. In some cases, longer duration leads to improved on-site sorting possibilities and degree of recycling and reuse of materials, resulting in reduced DWG. The demolition cost of a building is determined by a number of factors, such as labor cost, disposal cost, resale value of deconstructed materials (Dantata et al., 2005), and complexity of the work. Therefore, in some exceptional situations, developers may be willing to invest more in waste recycling and reuse, for instance by adopting deconstruction as the demolition method; as a result, less demolition waste will be sent to disposal facilities. For the demolition waste reduction, government may compensate for demolition contractors who involved financial investment in waste recycling and reuse, and/or less wasteful demolition methods. If doing so, the practices of recycling and reuse and adoption of demolition methods should be carefully identified and quantified to establish the criteria of compensation.

\subsection{Big data analytics in $C \& D$ waste management}

This study took advantage of an existing big dataset in C\&D waste management to understand the nature of DWG by connecting the dataset with other open databases. Big data can mitigate the potential bias in small sampling data and provide a fuller picture, which comes closer to objective truth. The big dataset in $\mathrm{C} \& \mathrm{D}$ waste management has been employed to empirically investigate the hidden causes of poor and superior management (Lu et al., 2015; Lu et al., 2016b) and to develop a forecasting method ( $\mathrm{Lu}$ et al., 2016a) to advance C\&D waste management. However, the systematic application of big data in C\&D waste management continues to be hindered by challenges such as privacy, technology, accuracy, and security. Building a big data system, which can acquire, store, and analyse data is more complicated than merely collecting existing big data for analysis but, if these challenges can be dealt with, such a system could lead to an era of data-driven decision-making. The big data in this study was generated from government management system, as a result, unintentionally contribute to the findings in the 
factors affecting DWG, which may serve as references for intervening the public policy-making. Therefore, establishing a big data system is necessary for the purpose of improving the examination of status quo, insightful decision making, and regulation formulation.

\subsection{Applications of this study and suggestions for future studies}

This study adopts Hong Kong as a case to examine the influencing factors on waste generation amount for construction projects. As contract sum and demolition duration are found as the indigenous factors, the total DWG can be predicted if contract sum and proposed demolition duration are given. Owing to the large volume of projects used, they can be generalized to projects in other countries or regions as two variables for prediction of total DWG amount for individual projects. However, the region, building category and public-private nature of the demolition project are the exogenous factors, which are in the context of Hong Kong with a high-density urban environment. Disparities of DWG caused by these factors can be different in other economies owing to their different political systems and urban planning. Yet, the development levels of different regions, the usage of buildings and the public-private nature of demolition buildings, which may lead to DWG disparities, serve as the factors that need serious considerations no matter doing studies, policy making or other related doings in other economies to alleviate environmental degradation and landfill space depletion caused by demolition waste. In the context of Hong Kong, developers and contractors can re-examine their waste management performance based on the average DWG level by region, category and public-private nature. Meanwhile, the government can target 'hot spot' regions, building categories and sectors: that is, $\mathrm{HK} \& \mathrm{KLN}$, industrial, residential, $\mathrm{R} \& \mathrm{C}$, and commercial, and the private sector, in its attempts to reduce $C \& D$ waste.

Although this study has successfully proven that DWG is highly affected by contract sum, duration, development level of the region, building type, and public-private nature of developer, these factors cannot account for all DWG therefore are not applicable for DWG projection in new demolition works due to the relatively low $\mathrm{R}$ square, 0.27 . This limitation is due to the difficulty of collecting data concerning other independent factors that potentially impact DWG such as building age, demolition method, and whether the new development on the demolition site is a green building. With more factors found, future studies are suggested to model the forecast of the DWG of individual projects with inputting the values of identified factors. Nevertheless, the factors found in this study are indeed causes lead to the disparities of the DWG of buildings in Hong Kong, and worthy considerations in C\&D waste management in other countries or cities.

\section{Conclusions}

This study identified the factors that impact the amount of waste generated by demolition projects by mining a big dataset generated in a five-year period from 2011 to 2015. By taking advantage of the big data, it was found that the exogenous factors (i.e. demolition cost and 
duration) and indigenous factors (i.e. regional development level, building category, and public-private nature of the development) significantly influence DWG amount. The exogenous factors indicate government should financially support demolition contractors in performing waste recycling and reuse, and/or adoption of less wasteful demolition methods. For the indigenous factors, it was found that DWG disparities are caused by conscious on-site and off-site waste segregation and recycling, but this is not substantiated by the existing evidence. In Hong Kong, it is suggested that the government focus on demolition waste reduction in projects located in $\mathrm{HK}$ and $\mathrm{KLN}$, and industrial, residential, $\mathrm{R} \& \mathrm{C}$ and commercial buildings developed by the private sector as these are the most wasteful demolition projects. The study not only offers reliable references for contractors, developers, and the government to make evidence-based policies and strategies and improve $C \& D$ waste governance in demolition projects, but also provides a big data approach to understanding the factors affecting DWG. Future studies are suggested to examine more factors that may influence DWG so as to provide more references for stakeholder interventions.

\section{Acknowledgement}

The research was supported by the National Nature Science Foundation of China (NSFC) (project no.: 71273219).

\section{References}

Andersen, F. M., Larsen, H., Skovgaard, M., Moll, S., and Isoard, S. (2007). A European model for waste and material flows. Resources, Conservation and Recycling, 49(4), 421-435.

Banias, G., Achillas, C., Vlachokostas, C., Moussiopoulos, N., and Papaioannou, I. (2011). A web-based decision support system for the optimal management of construction and demolition waste. Waste Management, 31(12), 2497-2502.

Bergsdal, H., Bohne, R. A., and Bratteb $\varnothing$, H. (2007). Projection of construction and demolition waste in Norway. Journal of Industrial Ecology, 11(3), 27-39.

Bohne, R. A., Bratteb $\varnothing$, H., and Bergsdal, H. (2008). Dynamic eco-efficiency projections for construction and demolition waste recycling strategies at the city level. Journal of Industrial Ecology, 12(1), 52-68.

Bossink, B. A. G., and Brouwers, H. J. H. (1996). Construction waste: quantification and source evaluation. Journal of Construction Engineering and Management, 122(1), 55-60.

Chen, H., Chiang, R. H. and Storey, V. C. (2012). Business Intelligence and Analytics: From Big Data to Big Impact. MIS Quart, 36(4), 1165-1188.

Cheng, J. C., and Ma, L. Y. (2013). A BIM-based system for demolition and renovation waste estimation and planning. Waste Management, 33(6), 1539-1551.

Construction Resources \& Waste Platform (CRWP) (2009). Overview of demolition waste in the UK. http://www.wrap.org.uk/sites/files/wrap/CRWP-Demolition-Report-2009.pdf, accessed on 12/01/2016.

Dantata, N., Touran, A., and Wang, J. (2005). An analysis of cost and duration for deconstruction 
and demolition of residential buildings in Massachusetts. Resources, Conservation and Recycling, 44(1), 1-15.

Department for Environment Food \& Rural Affairs (DEFRA) (2015). Digest of Waste and Resource Statistics $\quad-\quad 2015 \quad$ Edition, Jan 2015, https://www.gov.uk/government/uploads/system/uploads/attachment_data/file/482255/Dige st_of_waste_England_-_finalv3.pdf. Accessed on 12/12/2015.

Draper, N. R., Smith, H., and Pownell, E. (1966). Applied regression analysis (Vol. 3). New York: Wiley.

European Environment Agency (EEA) (1999). Baseline projections of selected waste streams Development of a methodology, Published: 10 Nov 1999, http://www.eea.europa.eu/publications/TEC28/, accessed on 14/01/2016

Gantz, J., and Reinsel, D. (2011) Extracting value from chaos. IDC iView, 1-12

Gobble, M. M. (2013). Big Data: The next big thing in innovation. Research-Technology Management, 56(1), 64-66.

Hampton, S. E., Strasser, C. A., Tewksbury, J. J., Gram, W. K., Budden, A. E., Batcheller. A. L., ... and Porter, J. H. (2013). Big data and the future of ecology. Frontiers in Ecology and the Environment, 11(3), 156-162.

Han, J., and Kamber, M. (2001). Data mining: concepts and techniques. 2001. Morgan Kauffman.

Han, J., Kamber, M., and Pei, J. (2011). Data mining: concepts and techniques. Elsevier.

Hong Kong Buildings Department (HKBD) (2004). Code of Practice (CoP) for Demolition of Buildings. http://www.bd.gov.hk/english/documents/code/Demolition_e2004.pdf

Howe, D., Costanzo, M., Fey, P., Gojobori, T., Hannick, L., Hide, W., ... and Rhee, S.Y. (2008). Big data: The future of biocuration. Nature, 455(7209), 47-50.

Katz, A., and Baum, H. (2011). A novel methodology to estimate the evolution of construction waste in construction sites. Waste Management, 31(2), 353-358.

Kern, A. P., Dias, M. F., Kulakowski, M. P., and Gomes, L. P. (2015). Waste generated in high-rise buildings construction: A quantification model based on statistical multiple regression. Waste Management, 39, 35-44.

Kitchin, R. (2014). The real-time city? Big data and smart urbanism. GeoJournal, 79(1), 1-14.

Kleemann, F., Lederer, J., Aschenbrenner, P., Rechberger, H., and Fellner, J. (2016). A method for determining buildings' material composition prior to demolition. Building Research \& Information, 44(1), 51-62.

Laney, D. (2001). 3-d data management: controlling data volume, velocity and variety. META Group Research Note, 6 February

Lauritzen, E. K., and Hahn, N. J. (1992). Building waste: generation and recycling. International solid waste management association year book 1991-1992, 48-58.

Lu, W., Chen, X., Ho, D. C., and Wang, H. (2016b). Analysis of the construction waste management performance in Hong Kong: the public and private sectors compared using big data. Journal of Cleaner Production, 112, 521-531.

Lu, W., Chen, X., Peng, Y., and Shen, L. (2015). Benchmarking construction waste management 
performance using big data. Resources, Conservation and Recycling, 105, 49-58.

Lu, W., Peng, Y., Chen, X., Skitmore, M. and Zhang, X. (2016a). The S-curve for forecasting waste generation in construction projects. Waste Management. Under review.

Lu, W., Yuan, H., Li, J., Hao, J. J., Mi, X., and Ding, Z. (2011). An empirical investigation of construction and demolition waste generation rates in Shenzhen city, South China. Waste Management, 31(4), 680-687.

Lu, W., and Tam, V. W. (2013). Construction waste management policies and their effectiveness in Hong Kong: A longitudinal review. Renewable and Sustainable Energy Reviews, 23, 214-223.

Lu, W., Webster, C., Peng Y., Chen, X., and Zhang, X (2016c). Estimating and calibrating the amount of building-related construction and demolition waste in urban China. International Journal of Construction Management, Forthcoming.

Manyika, J., Chui, M., Brown, B., Bughin, J., Dobbs, R., Roxburgh, C., and Byers, A. H. (2011). Big data: The next frontier for innovation, competition, and productivity. Report by McKinsey Global Institute.

Mayer-Schönberger, V., and Cukier, K. (2013). Big data: A revolution that will transform how we live, work, and think. Houghton Mifflin Harcourt.

McGregor, M., Washburn, H., and Palermini, D. (1993). Characterization of construction site waste. Final report presented to METRO, Solid Waste Department, Portland, OR.

Midland Realty (2016). Mitsui High-Tech Industrial Building. http://app.midland.com.hk/residential_ebook/default.jsp?estId=E07723\&lang=en, accessed on $25 / 01 / 2016$.

Mills, T. H., Showalter, E., and Jarman, D. (1999). Cost-effective waste management plan. Cost Engineering, 41(3), 35-43.

Murdoch, T. B., and Detsky, A. S. (2013). The inevitable application of big data to health care. Jama, 309(13), 1351-1352.

National Development and Reform Commission of China (NDRC) (2014). Annual report on the utilization of resources in China (in Chinese). http://www.sdpc.gov.cn/gzdt/201410/W020141009609718583202.pdf , accessed on 14/01/2016.

Peng, C. L., Scorpio, D. E., and Kibert, C. J. (1997). Strategies for successful construction and demolition waste recycling operations. Construction Management \& Economics, 15(1), 49-58.

Poon, C. S. (1997). Management and recycling of demolition waste in Hong Kong. Waste Management \& Research, 15(6), 561-572.

Poon, C. S., Ann, T. W., and Ng, L. H. (2001). On-site sorting of construction and demolition waste in Hong Kong. Resources, Conservation and Recycling, 32(2), 157-172.

Poon, C. S., Yu, A. T., and Ng, L. H. (2003). Comparison of low-waste building technologies adopted in public and private housing projects in Hong Kong. Engineering, Construction and Architectural Management, 10(2), 88-98.

Renovation in Building (2014). Annual Report 2014 RIB Software AG. 
https://irpages2.equitystory.com/download/companies/ribsoftware/Annual\%20Reports/DE0 00A0Z2XN6-JA-2014-EQ-E-00.pdf

Roche, T. D., and Hegarty, S. (2006). Best practice guidelines on the preparation of waste management plans for construction and demolition projects. http://www.envirocentre.ie/includes/documents/BPGConstructionand\%20demolition.pdf

Russom, P. (2011). Big data analytics. TDWI Best Practices Report, Fourth Quarter, 1-35.

Seo, S., and Hwang, Y. (1999). An estimation of construction and demolition debris in Seoul, Korea: waste amount, type, and estimating model. Journal of the Air \& Waste Management Association, 49(8), 980-985.

Shanghai Statistical Bureau (SSB) (2008 2015). Shanghai Statistics Yearbook. China Statistics Publisher.

Skoyles, E. R. (1976). Materials wastage-a misuse of resources. Building Research and Practice, 232-243 (July/August 1976).

Statistics Norway (2015). Waste from building and construction, 2013. Published on 09/06/2015. Available at: http://www.ssb.no/en/natur-og-miljo/statistikker/avfbygganl, accessed on 14/01/2016.

Treloar, G. J., Gupta, H., Love, P. E., and Nguyen, B. (2003). An analysis of factors influencing waste minimisation and use of recycled materials for the construction of residential buildings. Management of Environmental Quality: An International Journal, 14(1), 134-145.

Wang, J. Y., Touran, A., Christoforou, C., and Fadlalla, H. (2004). A systems analysis tool for construction and demolition wastes management. Waste Management, 24(10), 989-997.

Yuan, H. P., Shen, L. Y., Hao, J. J., and Lu, W. S. (2011). A model for cost-benefit analysis of construction and demolition waste management throughout the waste chain. Resources, conservation and recycling, 55(6), 604-612.

Zikopoulos, P., and Eaton, C. (2011). Understanding big data: Analytics for enterprise class hadoop and streaming data. McGraw-Hill Osborne Media.

Kofoworola, O. F., and Gheewala, S. H. (2009). Estimation of construction waste generation and management in Thailand. Waste management, 29(2), 731-738.

Ferguson, J. (1995). Managing and Minimizing Construction Waste: a Practical Guide. Thomas Telford.

Lu, W.S., and Yuan, H.P., 2011. A framework for understanding waste management studies in construction. Waste Management, 31 (6), 1252-1260.

Poon, C. S. (1997). Management and recycling of demolition waste in Hong Kong. Waste management \& research, 15(6), 561-572.

Wang, J. Y., Touran, A., Christoforou, C., and Fadlalla, H. (2004). A systems analysis tool for construction and demolition wastes management. Waste management, 24(10), 989-997.

Shi, J. and $\mathrm{Xu}, \mathrm{Y}$. (2006). Estimation and forecasting of concrete debris amount in China. Resources, Conservation and Recycling, 49(2), 147-158.

Poon, C. S., Ann, T. W., \& Ng, L. H. (2001). On-site sorting of construction and demolition waste in Hong Kong. Resources, conservation and recycling, 32(2), 157-172. 
Jaillon, L., Poon, C. S., \& Chiang, Y. H. (2009). Quantifying the waste reduction potential of using prefabrication in building construction in Hong Kong. Waste management, 29(1), 309-320.

Kibert, C. J., Chini, A., \& Languell, J. E. N. N. I. F. E. R. (2000, August). Deconstruction as an essential component of sustainable construction. In Proceedings of the second Southern African conference on sustainable development in the built environment, Pretoria (pp. 1-5).

Kourmpanis, B., Papadopoulos, A., Moustakas, K., Stylianou, M., Haralambous, K. J., \& Loizidou, M. (2008). Preliminary study for the management of construction and demolition waste. Waste Management \& Research, 26(3), 267-275.

Poon, C. S., Yu, A. T. W., See, S. C., \& Cheung, E. (2004). Minimizing demolition wastes in Hong Kong public housing projects. Construction Management and Economics, 22(8), 799-805.

Yuan, H. P., Shen, L. Y., Hao, J. J., \& Lu, W. S. (2011). A model for cost-benefit analysis of construction and demolition waste management throughout the waste chain. Resources, conservation and recycling, 55(6), 604-612.

Hendriks, C. F., \& Janssen, G. M. T. (2001). Construction and demolition waste: general process aspects. HERON, vol. 46 (2), 2001.

Mcdonald, B., and Smithers, M. (1998). Implementing a waste management plan during the construction phase of a project: a case study. Construction Management \& Economics, 16(1), 71-78.

Wang, J., Yuan, H., Kang, X., \& Lu, W. (2010). Critical success factors for on-site sorting of construction waste: a China study. Resources, Conservation and Recycling, 54(11), 931-936.

Lau, H.H., Whyte, A., Law, P.L., 2008. Composition and characteristics of construction waste generated by residential housing project. Int. J. Environ. Res. 2 (3), 261-268.

Wu, Z., Ann, T. W., Shen, L., \& Liu, G. (2014). Quantifying construction and demolition waste: an analytical review. Waste Management, 34(9), 1683-1692.

Tam, V. W., Tam, C. M., Zeng, S. X., \& Ng, W. C. (2007). Towards adoption of prefabrication in construction. Building and environment, 42(10), 3642-3654.

Bergsdal, H., Bohne, R.A., Brattebo, H., 2007. Projection of construction and demolition waste in Norway. J. Ind. Ecol. 11 (3), 27-39.

Llatas, C., 2011. A model for quantifying construction waste in projects according to the European waste list. Waste Manage. (Oxford) 31 (6), 1261-1276.

Yost, P.A., Halstead, J.M., 1996. A methodology for quantifying the volume of construction waste. Waste Manage. Res. 14 (5), 453-461.

HKEPD (2005). http://www.epd.gov.hk/epd/misc/cdm/scheme.htm, accessed on 2016/07/12.

Dantata, N., Touran, A., \& Wang, J. (2005). An analysis of cost and duration for deconstruction and demolition of residential buildings in Massachusetts. Resources, Conservation and Recycling, 44(1), 1-15.

Solís-Guzmán J, Marrero M, Montes-Delgado MV, and Ramírez-de-Arellano A (2009) A Spanish model for quantification and management of construction waste. Waste 
Management 29(9): 2542-2548.

McAfee, A., Brynjolfsson, E., Davenport, T. H., Patil, D. J., \& Barton, D. (2012). Big data. The management revolution. Harvard Bus Rev, 90(10), 61-67.

C\&SD (2016). Hong Kong in Figures, 2016 Edition. Census and Statistics Department Hong Kong Special Administrative Region. February 2016. Available at: http://www.statistics.gov.hk/pub/B10100062016AN16E0100.pdf, accessed on 20/07/2016.

Li, X., Lee, S. L., Wong, S. C., Shi, W., \& Thornton, I. (2004). The study of metal contamination in urban soils of Hong Kong using a GIS-based approach. Environmental Pollution, 129(1), 113-124.

Hong Kong Legislative Council (2011). Panel on Development Meeting on 20 April 2011: Background brief on revitalization of industrial buildings. http://www.legco.gov.hk/yr10-11/english/panels/dev/papers/dev0420cb1-1909-7-e.pdf

Civil Engineering and Development Department (CEDD) (2004). Guidelines for Selective $\begin{array}{lllll}\text { Demolition } & \& & \text { On } & \text { Site }\end{array}$ http://www.cedd.gov.hk/eng/services/recycling/doc/sel_dem.pdf

Fatta, D., Papadopoulos, A., Avramikos, E., Sgourou, E., Moustakas, K., Kourmoussis, F., ... \& Loizidou, M. (2003). Generation and management of construction and demolition waste in Greece - an existing challenge. Resources, Conservation and Recycling, 40(1), 81-91.

Bilal, M., Oyedele, L. O., Akinade, O. O., Ajayi, S. O., Alaka, H. A., Owolabi, H. A., ... \& Bello, S. A. (2016). Big data architecture for construction waste analytics (CWA): A conceptual framework. Journal of Building Engineering, 6, 144-156. 